\title{
Does self-ligating brackets type influence the hysteresis, activation and deactivation forces of superelastic NiTi archwires?
}

José Rino Neto1, Gilberto Vilanova Queiroz², João Batista de Paiva³, Rafael Yagüe Ballester

Objective: To compare hysteresis, activation and deactivation forces produced by first-order deformation of Contour 0.014-in NiTi wire (Aditek, Brazil) in four brands of self-ligating brackets: Damon MX, Easy Clip, Smart Clip and InOvation. Methods: Activation and deactivation forces were measured in an Instron universal tensile machine at $3 \mathrm{~mm} /$ minute speed to a total displacement of $4 \mathrm{~mm}$. Tests were repeated eight times for each bracket/wire combination. Statistical analysis comprised ANOVA and Tukey's multiple comparisons test. Results: Using a 4-mm deformation, mean activation forces increased in the following order: Damon $=222$ gf, Easy Clip = $228 \mathrm{gf}$, In-Ovation $=240$ gf and Smart Clip = 306 gf. The same order was observed for mean hysteresis values, i.e., $128 \mathrm{gf}, 140 \mathrm{gf}, 150 \mathrm{gf}$ and $206 \mathrm{gf}$, respectively. The respective values of deactivation forces for the Damon, Easy Clip, In-Ovation and Smart Clip brackets were $94 \mathrm{gf}, 88 \mathrm{gf}, 90 \mathrm{gf}$ and 100 gf. Conclusions: Brackets with higher activation forces were accompanied by higher hysteresis values, which resulted in clinically similar deactivation forces, regardless of the type of self-ligating brackets used.

Keywords: Corrective orthodontics. Orthodontic brackets. Orthodontic wires.

Objetivo: comparar as forças de ativação, desativação e histerese produzidas por deformação de primeira ordem do fio superelástico Contour NiTi 0,014” (Aditek ${ }^{\circledR}$ ) em quatro modelos de braquetes autoligáveis: Damon MX, Easy Clip, Smart Clip e In-Ovation. Métodos: as forças de ativação e desativação foram medidas em máquina universal de tração Instron com velocidade de $3 \mathrm{~mm} /$ minuto e deslocamento de $4 \mathrm{~mm}$. Em cada combinação braquete/fio foram executadas oito repetições. A análise estatística empregou ANOVA e o Teste de Comparações Múltiplas de Tukey. Resultados: com 4mm de deformação, as forças médias de ativação foram, em ordem crescente, Damon = 222gf, Easy Clip = 228gf, In-Ovation = 240gf e Smart-Clip = 306gf; a mesma ordem foi observada nas histereses médias, cujos valores foram, respectivamente, 128gf, 140gf, 150gf e 206gf; os valores das forças de desativação foram, respectivamente, 94gf, 88gf, 90gf e 100gf. Conclusão: os braquetes com maiores valores nas forças de ativação foram acompanhados por maiores valores na histerese, o que resultou em forças de desativação clinicamente semelhantes, independentemente do tipo de braquete autoligável utilizado.

Palavras-chave: Ortodontia corretiva. Fios ortodônticos. Aparelhos ortodônticos.

${ }^{1}$ Associate Professor, Department of Orthodontics, School of Dentistry, University of São Paulo (FOUSP).

${ }^{2} \mathrm{MSc}$ and $\mathrm{PhD}$ in Orthodontics, FOUSP.

${ }^{3}$ Full Professor, Department of Orthodontics, FOUSP.

${ }^{4}$ Full Professor, Department of Dental Materials, FOUSP.
How to cite this article: Rino Neto J, Queiroz GV, Paiva JB, Ballester RY. Does self-ligating brackets type influence the hysteresis, activation and deactivation forces of superelastic NiTi archwires? Dental Press J Orthod. 2013 JanFeb;18(1):81-5.

Submitted: January 16, 2010 - Revised and accepted: December 29, 2010

" The author reports no commercial, proprietary or financial interest in the products or companies described in this article.

Contact address: Gilberto Vilanova Queiroz

Via Piacenza, 144 -Jd. Paradiso - CEP: 13.331-545 - Indaiatuba/SP - Brazil

E-mail: gilbertovilanova@terra.com.br 


\section{INTRODUCTION}

Activation force is defined as the force required to deform an archwire when it is inserted into a misaligned bracket slot, ${ }^{8}$ whereas deactivation force is the force applied by the archwire on a misaligned bracket when it is reverting to its original shape. Friction in the contact region between wire and bracket is one of the factors affecting the magnitude of both activation and deactivation forces. The higher the friction, the greater the force required by an archwire to slide in the slots of brackets placed on anchorage teeth..$^{9,11}$

Friction in orthodontic sliding mechanics can be divided into two key components: Classic friction and binding. Classic friction is caused by the elastomeric ligatures compressing the archwire against the bottom of the bracket slot, ${ }^{9}$ which is controlled using self-ligating brackets, i.e., brackets that do not require the use of elastomeric ligatures given their own unique ligation devices. . $^{1,2,3,5}$

Binding, in turn, is a type of friction caused by archwire deformation (strain), with intensity depending on the force with which the archwire is pressed against the slots of the anchorage brackets., ${ }^{911}$ The magnitude of binding produced by first order deformation in Contour NiTi 0.014-in wire (Aditek) varies according to the type of self-ligating brackets used. ${ }^{14}$ Given that wire activation and deactivation forces are influenced by friction occurring between orthodontic wire and bracket ${ }^{9,11}$ it is important to evaluate if different self-ligating brackets affect the forces produced by wire deformation in superelastic NiTi wires.

The aim of this study was to compare the forces of activation, deactivation and hysteresis produced by the deformation of Contour 0.014-in NiTi wire in four different self-ligating brackets, i.e., Damon, Easy Clip, Smart Clip and In-Ovation.

\section{MATERIAL AND METHODS}

A device attached to the Instron universal tensile machine comprising five 0.022 × 0.028 -in brackets (central incisor, lateral incisor, canine, first and second premolars in the upper left quadrant) was used to compare the activation and deactivation forces produced by four types of self-ligating brackets: Damon MX (Ormco), Easy Clip (Aditek), In-Ovation (GAC) and Smart Clip (3M/Unitek).
The testing device consisted of four cylinders that could be moved vertically and two guiding slots with internal dimensions of $0.022 \times 0.028$-in positioned at the ends of the bracket area (Fig 1). In order to achieve parallelism and leveling between the bracket slots bonding was performed by simultaneously inserting a standard 0.022-in ruler into both the guiding slots and the bracket slots. Direct bonding of the brackets was performed individually and followed this sequence: Insertion of standard 0.022-in ruler into the guiding slots, application of cyanoacrylate (Superbonder, Henckel / Brazil) to the bracket base and positioning at the center of the cylinder, sliding of the cylinder until the bottom of the slot fit the 0.022-in standard ruler in its entire mesiodistal extension, determining the final bonding position (Fig 2). Direct bonding of the brackets with cyanoacrylate showed sufficient strength to stabilize the brackets during the mechanical tests, even in specimens without full contact between bonding surface and bracket base (Fig 2). The distance from bracket center to bracket center was $7.5 \mathrm{~mm}$.

To obtain the forces produced by the 0.014-in SE NiTi archwire in the different types of self-ligating brackets a support was developed whose upper portion was inserted into the Instron tensile machine and bottom portion displayed a surface where the canine would be bonded.

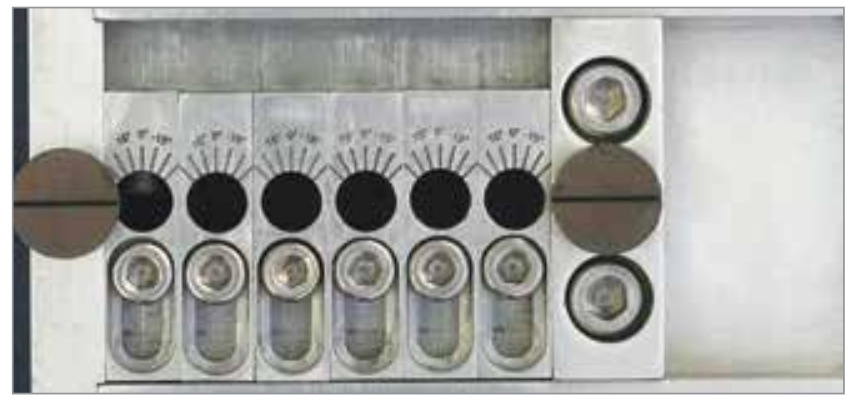

Figure 1 - Testing device.

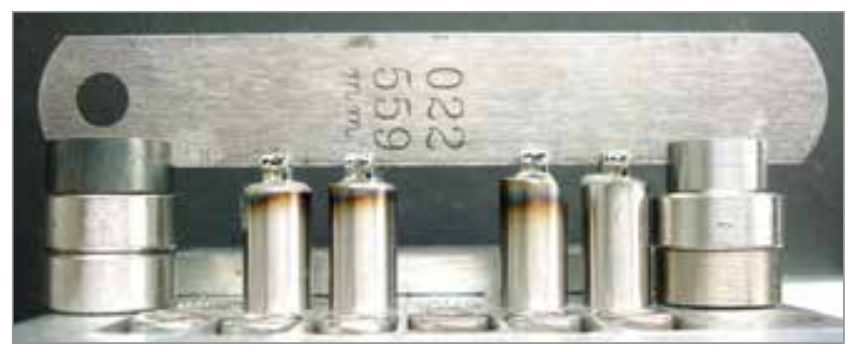

Figure 2 - Bracket positioning corresponding to incisors and premolars in a passive configuration. 
The canine bracket was bonded with light-curing resin in the following order (Fig 3):

»Insertion of $0.021 \times 0.025$-in rectangular stainless-steel wire into the bracket slot and stabilization with conventional elastomeric ligatures.

»Insertion of the same rectangular wire into the previously bonded brackets with the canine bracket at an equidistant position to the adjacent brackets (Fig 3A).

"Application of composite resin to the support attached to the Instron machine (Fig 3B).

" The support was raised until it touched the bracket, proceeding with curing of composite resin (Fig 3C).

This procedure sequence ensured parallelism between the slot of the canine bracket, attached directly to the Instron machine, and the slots of the four brackets bonded to the cylinders.

A straight segment of Contour NiTi wire (Aditek) with round 0.014-in cross-section and $12 \mathrm{~cm}$ length was employed in all mechanical tests. The superelastic Contour NiTi wire, classified as active austenitic, was stabilized inside the slots by means of the lids or clips (ligation device) of the self-ligating brackets.

A model 5565 Instron universal mechanical testing machine was used with a load cell of 500 Newtons and crosshead speed of $0.05 \mathrm{~mm} / \mathrm{second}$. The forces were recorded every $0.1 \mathrm{~mm}$ during activation cycles until reaching the maximum displacement of $4.5 \mathrm{~mm}$, and during deactivation back to zero. A comparison between activation and deactivation forces performed at $4 \mathrm{~mm}$ deformation during inferior displacement of the canine bracket, which simulated a lingual canine placement and a first order deformation.

Eight tests were performed for each bracket type replacing the archwires for each test. The tests were performed in a dry medium at a temperature between 24 and 26 Celsius degrees.

\section{Statistical analysis}

The values for means, standard deviations and amplitudes were calculated and normality tests applied for each orthodontic wire-bracket combination. The differences between the four self-ligating brackets were tested by comparing the mean values with ANOVA, and Tukey's multiple comparisons test was applied to verify between which bracket brands the differences occurred.

The analyses were performed with SAS (Statistical Analysis System) 8.0 software. All results for $\mathrm{p}$ values lower than 0.05 were considered statistically significant.

\section{RESULTS}

Figure 4 shows the average load-deflection curves for the four self-ligating brackets assessed. The Contour 0.014-in NiTi archwire exhibited activation and deactivation plateaus in all tests, confirming its superelastic properties.

Descriptive analysis of the activation, deactivation and hysteresis forces for the 0.014-in NiTi wire are displayed in Table 1 . The lowest mean activation force was $228 \mathrm{gf}$, obtained using Damon brackets, while the highest was 312 gf, using Smart Clip brackets. Deactivation forces showed mean values between 88 and 100 gf while hysteresis exhibited greater fluctuations, with values between $134 \mathrm{gf}$ (Damon) and 212 gf (Smart Clip). The reduced data scatter found in the standard deviations and amplitudes indicates adequate repeatability of the method used for the mechanical tests. ${ }^{8}$

Total results of Tukey's multiple comparisons test are shown in Table 2. Overall, the groups showed statistically significant differences in hysteresis and activation forces while deactivation forces were similar, except between Easy Clip and Smart Clip brackets.
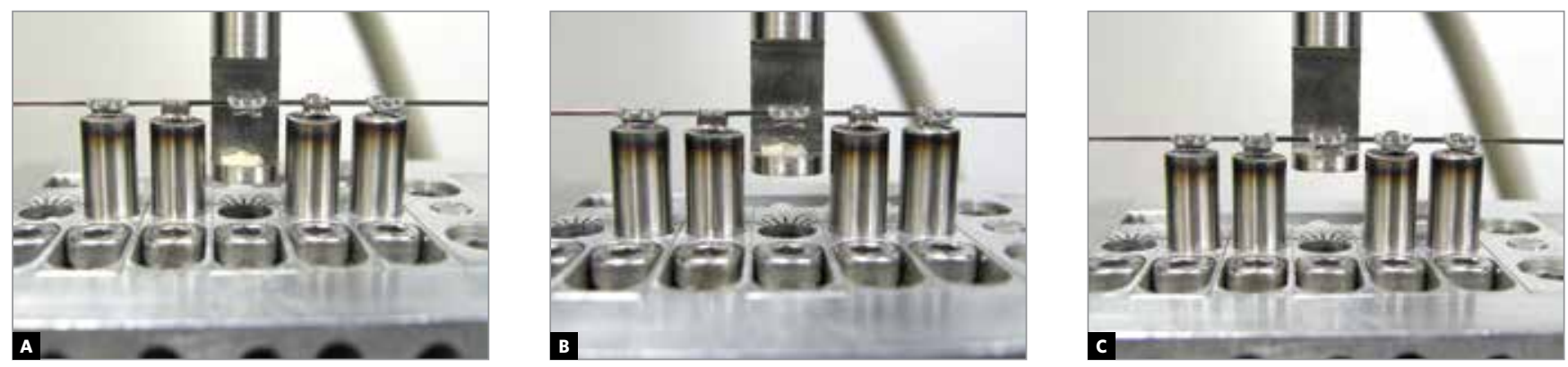

Figure 3 - A) Inferior displacement of the support and application of composite resin. B) Support rising. C) Placement of the canine bracket in a passive configuration. 

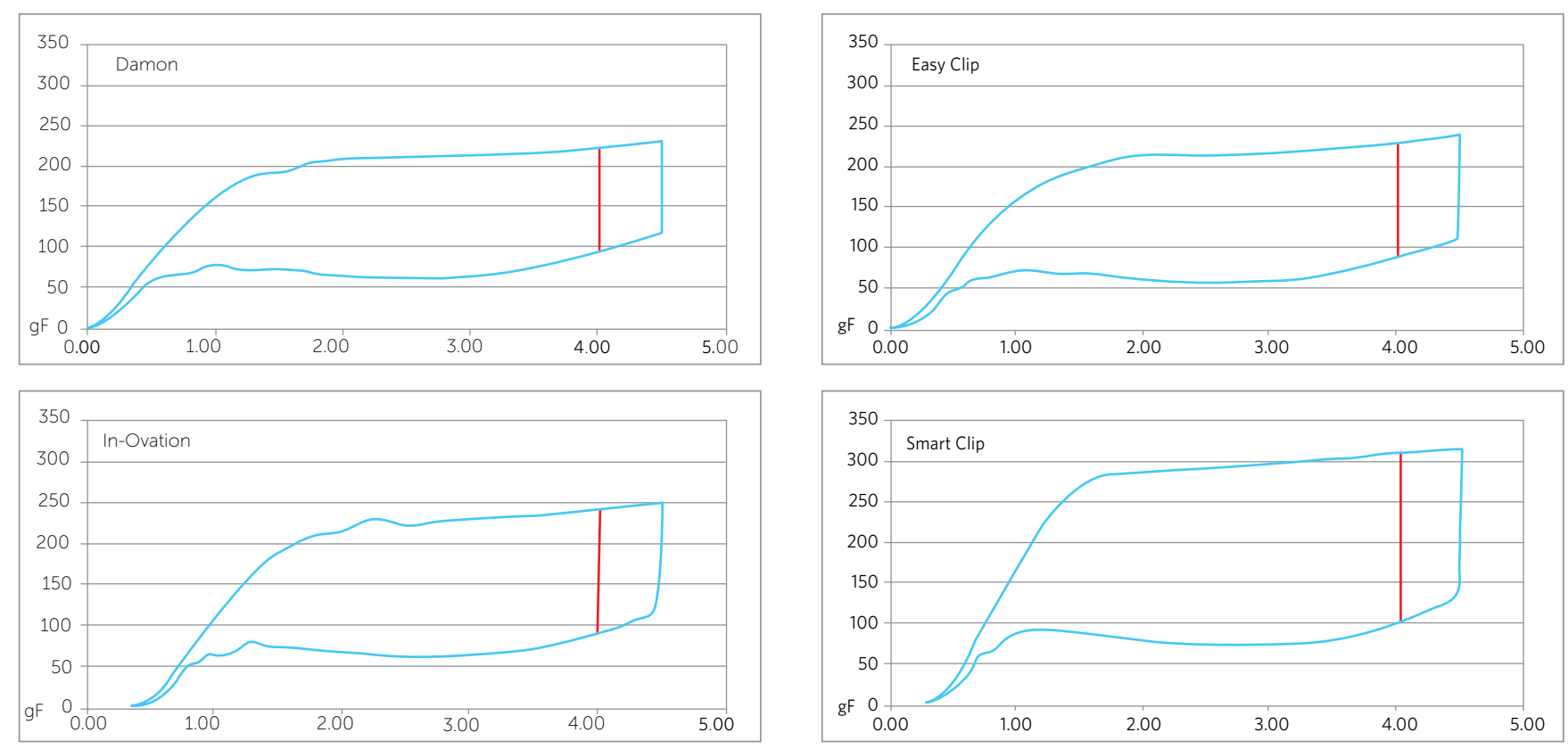

Figure 4 - Load/deflection curves for 0.014-in NiTi wire with Damon, Easy Clip, In-Ovation and Smart Clip brackets. The red line indicates hysteresis at a 4 mm deflection.

Table 1 - Mean, standard deviation (SD) and amplitude (A) in grams/force with $4 \mathrm{~mm}$ deflection.

\begin{tabular}{|c|c|c|c|c|c|c|}
\hline & \multicolumn{2}{|c|}{ Activation } & \multicolumn{2}{|c|}{ Deactivation } & \multicolumn{2}{|c|}{ Hysteresis } \\
\hline & $\begin{array}{c}\text { Mean } \pm \\
\text { SD }\end{array}$ & $\mathbf{A}$ & $\begin{array}{c}\text { Mean } \pm \\
\text { SD }\end{array}$ & A & $\begin{array}{c}\text { Mean } \pm \\
\text { SD }\end{array}$ & A \\
\hline Damon & $228 \pm 6$ & 17 & $94 \pm 4$ & 13 & $134 \pm 6$ & 16 \\
\hline Easy Clip & $235 \pm 5$ & 17 & $88 \pm 2$ & 6 & $147 \pm 6$ & 21 \\
\hline In-Ovation & $247 \pm 6$ & 21 & $90 \pm 2$ & 7 & $157 \pm 5$ & 16 \\
\hline Smart Clip & $312 \pm 14$ & 35 & $100 \pm 4$ & 13 & $212 \pm 10$ & 26 \\
\hline
\end{tabular}

\section{DISCUSSION}

Superelastic NiTi archwires exhibit plateaus of constant forces that allow orthodontists to select the ideal force according to the desired kind of movement. ${ }^{10}$ To achieve this goal it is important to define whether the load-deflection curve of superelastic NiTi wire is constant or varies when different brands of self-ligating brackets are used.

Activation force is the force required to insert the archwire into the bracket slot. One of the factors influencing the magnitude of activation force is the friction force present in the wire-bracket interface. The higher the friction the greater the force required for the archwire to slide inside the slots of the brackets placed on the anchorage teeth, resulting in a higher activation force. ${ }^{9,11}$ A previous study ${ }^{14}$ found that a $4 \mathrm{~mm}$ horizontal deformation of the Contour 0.014-in NiTi wire produced significantly different friction forces between self-ligating brackets, with
Table 2 - Results of Tukey's multiple comparisons test between self-ligating brackets $(p<0.05)$.

\begin{tabular}{cccccccc}
\hline & \multicolumn{2}{c}{ Activation } & \multicolumn{2}{c}{ Deactivation } & \multicolumn{2}{c}{ Hysteresis } \\
& Mean & $\neq$ Sig. & Mean & $\neq$ Sig. & Mean & $\neq$ Sig. \\
\hline Damon (a) & 228 & c,d & 94 & -- & 134 & b,c,d \\
\hline Easy Clip (b) & 235 & d & 88 & d & 147 & a,d \\
\hline In-Ovation (c) & 247 & a,d & 90 & -- & 156 & a,d \\
Smart Clip (d) & 312 & a,b,c & 100 & b & 211 & a,b,c \\
\hline
\end{tabular}

values increasing in the following order: Damon, Easy Clip, In-Ovation and Smart Clip. This outcome raised the hypothesis that the activation force might also vary depending on the use of different self-ligating brackets. The results of this study confirm this hypothesis. When subjected to $4 \mathrm{~mm}$ standardized horizontal deformations, the Contour 0.014-in NiTi archwire exhibited increasing activation forces in the same sequence found for friction forces between self-ligating brackets: Damon, Easy Clip, In-Ovation and Smart Clip.

Although increases in activation force may aggravate patient discomfort upon archwire insertion, ${ }^{8}$ such fact bears limited importance since the actual forces delivered to the periodontium during orthodontic treatment are the deactivation forces. ${ }^{13}$ Thus, within a strictly clinical perspective, comparisons between deactivation forces of self-ligating brackets are more relevant. 
When comparing the deactivation forces produced by superelastic NiTi wires in different self-ligating brackets, Franchi et $\mathrm{al}^{4}$ found no clinically relevant differences. This study found statistically significant differences between mean deactivation forces for the Easy Clip and Smart Clip brackets. However, since this difference only amounted to $12 \mathrm{gf}$, a value insufficient to produce clinically relevant differences, the deactivation forces found between Damon, Easy Clip, In-Ovation and Smart Clip brackets were considered similar. Therefore, from a clinical standpoint, the significant differences found for the activation forces between self-ligating brackets did not influence the magnitude of the deactivation forces.

Mechanical hysteresis - defined as the force difference between the archwires' activation and deactivation plateaus at identical deflection ${ }^{6,7}$ — was significantly different between the self-ligating brackets, with lower values for the Damon bracket, intermediate values for Easy Clip and In-Ovation, and higher values for Smart Clip brackets. This indicates that the significant differences found in activation forces between the self-ligating brackets were absorbed by the NiTi SE wire, thereby rendering deactivation forces clinically similar. Such behavior may be explained by the special mechanical properties of superelastic nickel-titanium wires.

Superelastic NiTi wire conforms to Hooke's law in its initial deformation, when an increase in load results in proportional wire deformation. After this first phase, when deformation reaches a critical limit a second stage begins characterized by the transformation of the wire's crystal structure from austenite to martensite. During this transition wire stiffness collapses, causing progressive deformation of the archwire with almost constant force, a phenomenon evidenced by a plateau in the wire's activation force. ${ }^{6,712}$ The martensitic phase is unstable in the absence of force. Therefore, as soon as wire compression ends, the process is reversed with a transformation from the martensitic phase into austenitic. Reversal of the crystal structure requires less energy, which justifies the presence of marked hysteresis in the early deactivation stage.

Although its participation in this process has not yet been clearly defined, the friction force that opposes the archwire sliding is one of the factors that influence the profile of the load-deflection curve and hysteresis magnitude. ${ }^{6}$

Considering that deactivation forces are of most relevance from a clinical point of view and that they proved similar between Damon, Easy Clip, In-Ovation and
Smart Clip brackets, the results suggest that the self-ligating brackets assessed in this study are equivalent, regardless of the activation forces. It should be noted however that wire deformation produces moments of force both in the misaligned tooth and in the adjacent anchorage teeth. These factors were not addressed in this research.

\section{CONCLUSIONS}

High activation force values of the Contour 0.014-in $\mathrm{NiTi}$ wire were accompanied by higher hysteresis values, which resulted in clinically similar deactivation forces, regardless of type of self-ligating brackets used.

\section{REFERENCES}

1. Baccetti T, Franchi L. Friction produced by types of elastomeric ligatures in treatment mechanics with the preadjusted appliance. Angle Orthod. 2006:76(2):211-6.

2. Cacciafesta V, Sfondrini MF, Ricciardi A, Scribante A, Klersy C, Auricchio F. Evaluation of friction of stainless steel and esthetic self-ligating brackets in various bracket-archwire combinations. Am J Orthod Dentofacial Orthop. 2003:124:395-402.

3. Demicheli M, Migliorati MV, Balboni C, Biavati AS. Confronto tra differenti sistemi bracket/filo/legatura - Misurazione in vitro dell'attrito su un'intera arcata. Mondo Ortod. 2006:4:273-89.

4. Franchi L, Baccetti T, Giuntini V. Forces released by nonconventional bracket or ligature systems during alignment of buccally displaced teeth. Am J Orthod Dentofacial Orthop. 2009;136:316.e1-e6.

5. Gandini P, Orsi L, Bertoncini C, Massironi S, Franchi L. In vitro frictional forces generated by three different ligation methods. Angle Orthod. 2008;78:917-21

6. Garrec P, Jordan L. Stiffness in bending of a superelastic Ni-Ti orthodontic wire as a function of cross-sectional dimension. Angle Orthod. 2004:74:691-6.

7. Garrec P, Tavernier B, Jordan L. Evolution of flexural rigidity according to the cross-sectional dimension of a superelastic nickel titanium orthodontic wire. Eur J Orthod. 2005:27:402-7.

8. Kasuya S, Nagasaka S, Hanyuda A, Ishimura S, Hirashita A. The effect of ligation on the load-deflection characteristics of nickel-titanium orthodontic wire. Eur J Orthod. 2007:29(6):578-82

9. Kusy R, Whitley, JQ. Influence of archwire and bracket dimensions on sliding mechanics: Derivations and determinations of the critical contact angles for binding. Eur J Orthod. 1999:21:199-208.

10. Mallory DC, English JD, Powers JM, Brantley WA, Bussa HI. Forcedeflection comparison of superelastic nickel-titanium archwires. Am J Orthod Dentofacial Orthop. 2004;126:110-2.

11. Meling TR, Odegaard J, Holthe K, Segner D. The effect of friction on the bending stiffness of orthodontic beams: A theoretical and in vitro study. Am J Orthod Dentofacial Orthop. 1997:112:41-9.

12. Miura F, Mogi M, Ohura Y, Hamanaka H. The super-elastic property of the Japanese NiTi alloy wire for use in orthodontics. Am J Orthod Dentofacial Orthop. 1986:90:1-10.

13. Nakano H, Satoh K, Norris R, Jin T, Kamegai T, Ishikawa F, et al. Mechanical properties of several nickel-titanium alloy wires in three-point bending tests. Am J Orthod Dentofacial Orthop. 1999:115:390-5.

14. Queiroz G, Rino JN, Paiva JB, Ballester RY. Estudo comparativo da força de atrito produzida pela deformação de arco NiTi em diferentes braquetes ortodônticos. Avaliação in vitro. Dental Press J Orthod. 2012;17(4):45-50. 